\title{
Electrochemical Behavior of Norfloxacin and Its Determination at Poly(methyl red) Film Coated Glassy Carbon Electrode
}

\author{
Ke-Jing Huang, Chun-Xuan Xu, and Wan-Zhen Xie \\ College of Chemistry and Chemical Engineering. Ninvang Normal Lniversitv, Hintang $46+000, P . R$. China \\ E-mail: kejinghuanga $163 . \mathrm{com}$ \\ Recened Nowember 2, 2007
}

\begin{abstract}
A poly (methyl red) film-modified glassy carbon electrode (PMRE) was fabricated for determination of norfloxacin (NFX). The electrochemical behavior of NFX was investigated and a well-defined oxidation peak with high sensitivity was observed at the film electrode. PMRE greatly enlanced the oxidation peak current of NFX owing to the extraordinary properties of poly (methyl red) film. Based on this. a sensitive and simple voltammetric method was developed for measurement of NFX. A sensitive linear voltammetric response for NFX was obtained in the concentration range of $1 \times 10^{-6}-1 \times 10^{-4} \mathrm{~mol} / \mathrm{L}$ and the detection limit was $1 \times 10^{-7}$ $\mathrm{mol} / \mathrm{L}$ using linear sweep voltammetry (LSV). The proposed method possessed advantages such as low detection limit. fast response. low cost and simplicity. The practical application of this new analytical method was demonstrated with NFX phanmaceuticals.
\end{abstract}

Key Words : Norfloxacin, Methỵl red. Voltammetric determunation. Chenically-modified electrode

\section{Introduction}

Fluoroquinolones are important antibacterial agents developed in the 1980s, and have been widely applied in veterinary and human medicine. Almost all of the clinically useful quinolones bear a fluorine atom in the C-6 position and thus these antibacterial agents are called fluoroquinolones. Norfloxacin (NFX), 1-ethy 1-6-fluoro-1.4-dihydro-4oxo-7-(1-piperazinyl)-3-quinolonecarboxylic acid is a fluoroquinoline carboxylic acid. The chemical structure is shown in Figure 1. It has effective against gram-positive and gram-negative bacteria by inhibition of their NAD gyrase. a critical enzyme to bacterial chromosome replication. i.2 NFX is widely used in the treatment of respiratory tract and urinary tract infections. ${ }^{3}$ Obviously, monitoring of OFX concentrations may be valuable to adjust the drug dosage and to study drug-drug interactions when co-administered with other anti-tuberculosis drugs for take-medicine person. Therefore. the widespread use of NFX and the need for clinical and pharmacological study require fast and sensitive analytical methods for its determination.

To date numerous methods have been reported for the determination of NFX in pharmaceutical preparations or biological samples. It mainly includes high-performance liquid chromatography (HPLC) ${ }^{4-6}$ spectrophotometry ${ }^{7-16}$ spectrofluorimetry ${ }^{11-14}$ and capillary electrophoresis (CE). ${ }^{15.16}$ HPLC has been widely applied because of its selectivity and<smiles>CCN1CC(C(=O)O)C(=O)c2cc(F)c(N3CCNCC3)cc21</smiles>

Figure 1. Chemical structure of norfloxacin. the ability to minimize interferences. However. it is timeconsuming solvent-usage intensive and expensive (require expensive devices and maintenance). Electrochemical detection of analyte is a very elegant method in analytical chenistry. However, the voltammetric response of NFX is not satisfactory at the bare electrode. Very few studies have been reported for electrochemical detemination of NFX. ${ }^{17.18}$

Recently, electrodes coated with electropolymerized conducting polymer films have been paid great attention due to their unique physical and chemical properties and electrocatalysis. ${ }^{19.21}$ Many studies have indicated that polymer film modified electrodes show an enhanced response for the determination of various important biological and clinical species. The thickness. permeation and charge transport characteristics of the polymeric films can be controlled by the potential and current applied. In general. polymerization of dyes can form a cross-linked oligomer which leads to the enhancement of its adsorptive ability. ${ }^{21}$ Methyl-red (2-[4(dimethylamino)phenylazo]benzoic acid) with molecular fomula of $\mathrm{NC}_{6} \mathrm{H}_{4} \mathrm{COOH}$ is a organic dye and typical aromatic azo compound. Its chemical structure is illustrated in Figure 2.

To the best of our knowledge, no study involving a poly(methyl red) film modified electrode for detemination of NFX has been reported. In this paper. we present and discuss the electrochemical detection of NFX based on a poly (methyl red) film coated GCE (PMRE) for the first time. The monomer of methyl red has a dimethyl amine group. an azo group and a carboxyl group. which is promising to

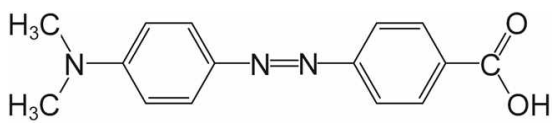

Figure 2. Chemical structure of methy l red. 
adsorb NFX. The electrochenical behavior of NFX on the PMRE strongly reveals that the electrochenical oxidation of NFX is facilitated. A voltanumetric method is developed for the direct measurement of NFX after optimizing the experimental parameters. This newly proposed method possesses many advantages such as low detection limit. fast response. low cost and simplicity compared with other published methods.

\section{Experimental Section}

Apparatus. Cyclic voltammetry $(\mathrm{CV})$ and linear sweep voltanumetry (LSV) experiments were performed on a CHI660A electrochemical workstation (CH Instrumental. USA) coupled with a conventional three-electrode cell. The working electrode was a poly (methyl red) film-modified glassy carbon electrode (PMRE) or bare GCE. The auxiliary electrode was a platinum wire and the reference electrode was a $\mathrm{Ag} / \mathrm{AgCl}$. All the potentials in this paper are given against the $\mathrm{Ag} / \mathrm{AgCl}$.

Reagents. Norfloxacin was obtained from National institute for the control of pharnacentical and biological products (Beijing. China). A $1 \times 10^{-3} \mathrm{~mol} / \mathrm{L}$ stock solution of NFX was prepared in $0.01 \mathrm{~mol} / \mathrm{L}$ hydrochloric acid. The stock standard solution was stored in a refrigerator at approximately $4^{\circ} \mathrm{C}$. Working standard solutions were prepared by suitable dilution of the stock standard solution with twice-distilled water. Acetate buffer $(0.05 \mathrm{~mol} / \mathrm{L}, \mathrm{pH} 4.4)$ was prepared with sodium acetate and acetic acid. All the chemicals used were of analytical grade and used directly without purification

Modification procedure. Before the electropolymerization of methyl red. a glassy carbon electrode $(3 \mathrm{~mm}$ in diameter) was polished to a mirror with polish paper and alunina pastes of 0.5 and $0.1 \mu \mathrm{m}$ ( $\mathrm{CH}$ Instruments. USA). and cleaned thoroughly in an ultrasonic cleaner with $\mathrm{I}: \mathrm{I}$ nitric acid solution. alcohol, and water, sequentially. Then the treated electrode was electroactivated by successive cyclic voltammetric sweeps in $0.1 \mathrm{~mol} / \mathrm{L}$ sulfuric acid solution between -1.0 and $+2.2 \mathrm{~V}$ until the voltammograms were unchanged. The resulted glassy carbon electrode was then scanned in an aqueous solution containing $1.0 \mathrm{mmol} / \mathrm{L}$ of methyl-red and $0.5 \mathrm{~mol} / \mathrm{L}$ of $\mathrm{NaNO}_{3}$ within the scan potential range of $-1.0-2.2 \mathrm{~V}$ at a scan rate of $100 \mathrm{ml}^{-1}$ for 25 cycles. Finally. the film was washed with water for several times to remove physically adsorbed material.

Analytical procedure. The PMRE was first activated in an acetate buffer $(0.05 \mathrm{~mol} / \mathrm{L}$. $\mathrm{pH} 4.4)$ by cyclic voltammetric sweeps between 0 and $1.4 \mathrm{~V}$ until stable cyclic voltammograms were obtained. and then transferred into another $10 \mathrm{~mL}$ of supporting electrolyte solution containing a certain concentration of NFX. Voltanmograms were recorded after $70 \mathrm{~s}$ of accumulation at $-1.2 \mathrm{~V}$ and a $2 \mathrm{~s}$ quiescence period. Cyclic voltammograms or linear sweep voltammograms from 0.2 to $1.4 \mathrm{~V}$ was recorded for determination of NFX. The oxidation peak current employed for the analysis was measured at $1.12 \mathrm{~V}$. The same procedure was applied in the samples analysis. Removal of oxygen was achieved by using high purity $\mathrm{N}_{2}$. For electrode regeneration, the working electrode was transferred to a blank electrolyte solution and series of cyclic scans was continued until a voltammogram corresponding to the residual current was obtained The electrode was then ready for use in a next measurement cycle.

Sample preparation. The average tablet and capsule weights were calculated from the weight of 20 tablets and capsules. An accurately weighed portion of each homogenized power containing $200 \mathrm{mg}$ NFX was sonicated in 5 $\mathrm{mL}$ of $0.01 \mathrm{~mol} / \mathrm{L} \mathrm{HCl}$ solution and transferred to a $50 \mathrm{~mL}$ flask. The resulted solution was diluted with twice-distilled water. The mixture was filtered and an aliquot of the resulted solution was transferred to a voltanmetric cell containing 10 $\mathrm{mL}$ of acetate buffer ( $\mathrm{pH} 4.4)$ so that final concentration was in the working range. The linear sweep voltammograms were then recorded after $70 \mathrm{~s}$ preconcentration time at -1.2 $V$. The content of NFX in tablet and capsule was determined referring to the regression equation

\section{Results and Discussion}

Electrochemical modification of methyl red on GCE. Inmobilization of methyl red $\left(1.0 \times 10^{-3} \mathrm{~mol} / \mathrm{L}\right)$ on the surface of GCE was performed by cyclic voltanmetry in a $\mathrm{NaNO}_{3}(0.5 \mathrm{~mol} / \mathrm{L})$. The film was grown on GCE by different segments of cyclic voltanmetric scans between -1.0 and $2.2 \mathrm{~V}$. There was not any peak obtained at first two segments of cyclic voltammetric scans. With the increase in the cyclic number of voltammetric scans. two oxidation peaks were gradually observed at $0.289 \mathrm{~V}$ and $1.536 \mathrm{~V}$. and one reduction peak was observed at $-0.277 \mathrm{~V}$ (Figure 3), respectively. The redox peak current increased with the enhancement of the cyclic number of voltanmetric scans. indicating that an electroconductive film formed on the electrode surface. The film was washed with water to remove the remaining methyl red monomers after immobilization. A thin film could be seen at the electrode surface after dried in air.

The thickness of the film could be controlled by the cyclic

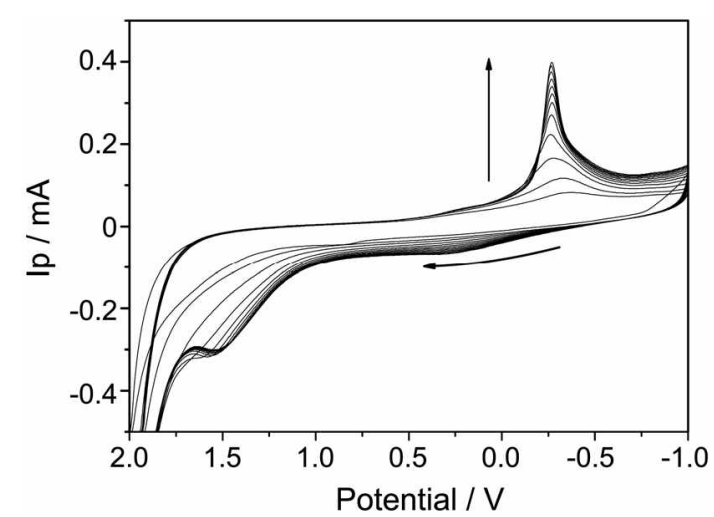

Figure 3. Cyclic voltammogram tor the preparation of poly(methyl red) film modified GCE. Scan rate: $100 \mathrm{mVs}^{-1}$ : $\mathrm{C}_{\text {(methyl redl }}=1.0^{\circ} \times$ $10^{-3} \mathrm{~mol} / \mathrm{L}$ : Supporting electrolyte: $\mathrm{NaNO}_{3}$ solution $(0.5 \mathrm{~mol} / \mathrm{L})$. 


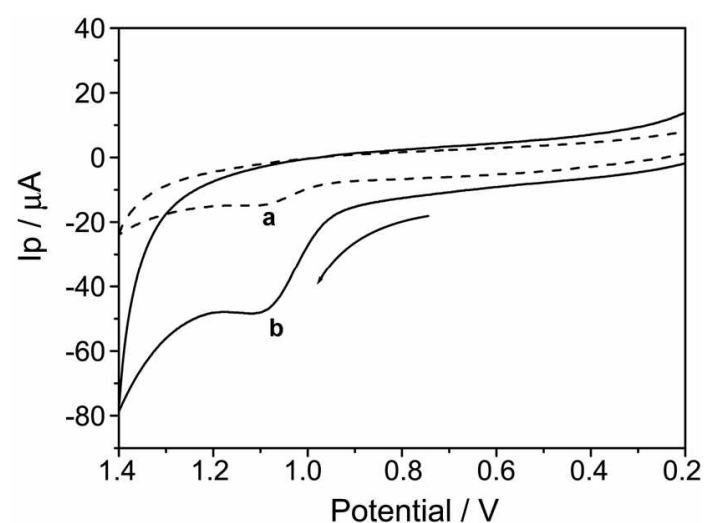

Figure 4. Typical cyclic voltammograms of $1.0 \times 10^{-4} \mathrm{~mol} / \mathrm{L}$ norfloxacin at a GCE (a); and polv(methyl red) tilm modified GCE (b) in acetate buffer $(0.05 \mathrm{~mol} / \mathrm{L}, \mathrm{pH} 4.4)$. Scan rate: $100 \mathrm{~m} \mathrm{~V} / \mathrm{s}$.

number of voltanmetric scans and the concentration of methyl red. The conducting polymer layer may increase the charge transfer current as well as capacitive current. The optimal thickness of poly(methyl red) on GCE was evaluated by determining fixed concentration of NFX. The results showed that 25 segments of cyclic voltanmetric scans between -1.0 and $2.2 \mathrm{~V}$ in the solution which contained 1.0 $\times 10^{-3} \mathrm{~mol} / \mathrm{L}$ of methyl red and $0.5 \mathrm{~mol} / \mathrm{L} \mathrm{NaNO}$ gave the biggest oxidation peak current of NFX. So above conditions were used to prepare the film electrode.

Electrochemical behavior of norfloxacin at poly(methyl red) film-modified GCE. The electrocatalytic activity of PMRE toward NFX was examined by cyclic voltanmetry. Figure 4 showed the cyclic voltanmograms responses of 0.1 Immol/L NFX at a bare GCE and PMRE in buffer solution $\left(\mathrm{pH}^{4} .4\right)$ at scan rate $100 \mathrm{mV} \mathrm{s}^{-1}$. The film electrode exhibited significant oxidation currents starting around $1.12 \mathrm{~V} w$. $\mathrm{Ag} / \mathrm{AgCl}$ and no reduction signal was observed in the reversed scan. In contrast, low redox activity was observed at the unmodified $\mathrm{GC}$ electrode and the oxidation current starting around $1.20 \mathrm{~V}$. A slightly negative shift of the oxidation peak potential for NFX and dramatic increase of current were obtained at PMRE. $1 \times 10^{-4} \mathrm{~mol} / \mathrm{L}$ NFX gave a $5.20 \mu \mathrm{A}$ oxidation peak current at the bare $\mathrm{GC}$ electrode. However. at the modified GCE the oxidation peak current increased to $26.70 \mu \mathrm{A}$. NFX can be adsorbed on the electrode more easily, and this leads to higher sensitivity when compared to the bare electrode.

The experiments also showed that no reduction peak was observed in the reverse scan at the PMRE. suggesting that the electrochemical reaction was a totally irreversible process. Nevertheless. it was found the oxidation peak current of NFX showed a remarkable decrease during the successive cyclic voltammetric sweeps. The peak current decreased slightly' after the second sweep and funally remained unchanged. This phenomenon may be caused by the fact that the adsorption of NFX or its oxidative product occurs at the film electrode surface. Thus. the oxidation peak current in the first anodic sweep was recorded for NFX analysis in the following studies.

Linear sweep voltammetry (LSV) was also applied to

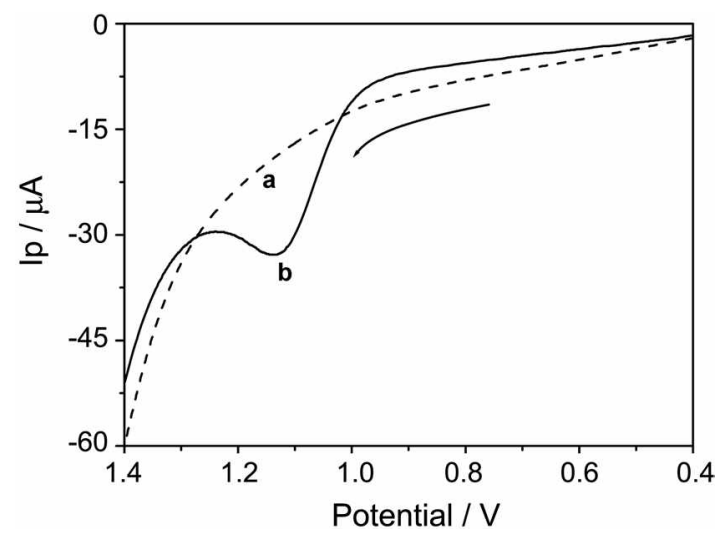

Figure 5. Linear sweep voltammograms of poly(methyl red) film modified GCE. Curve (a) (dot line): acetate buffer $(0.05 \mathrm{~mol} / \mathrm{L}, \mathrm{pH}$ 4.4 j; Curve (b) (solid line j: $1.0 \times 10^{-4} \mathrm{~mol} / \mathrm{L}$ norfloxacin in acetate

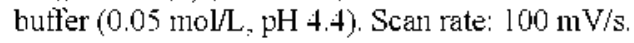

investigate the electrochemical behavior of NFX at the PMRE and the same results were obtained. The LSV peak of NFX at the bare GC electrode was broad, and the peak shape was not good. However. the oxidation peak current of NFX at the film electrode increased significantly under identical conditions. Figure 5 showed the linear sweep voltammograms of a PMRE in an acetate buffer $(0.05 \mathrm{~mol} / \mathrm{L}$. $\mathrm{pH} 4.4)$ in the presence and absence of NFX. No redox peak was observed (dot line) within the potential window from 0.4 to 1.4 V. However. a well defined oxidation peak with very high current is observed at $1.12 \mathrm{~V}$ (solid line) in the case of 1 $\times 10^{-4} \mathrm{~mol} / \mathrm{L}$ NFX. This peak was performed to determine NFX in the further experiments.

The oxidation of NFX at acid pH at the film coated glassy carbon electrode was reported. ${ }^{17}$ Therefore. the effect of $\mathrm{pH}$ $(<7)$ on the oxidation belavior of NFX was investigated. The dependence of the peak current on the $\mathrm{pH}$ value was shown in Figure 6 . The oxidation peak current increased when $\mathrm{pH}$ was in the range of 3.5-4.4. However, it clearly decreased when $\mathrm{pH}$ was more than 4.4. Therefore. $\mathrm{pH} 4.4$ was chosen for the further experiments.

The effect of scan rate on the electro-oxidation of NFX at the modified electrode was investigated by linear sweep

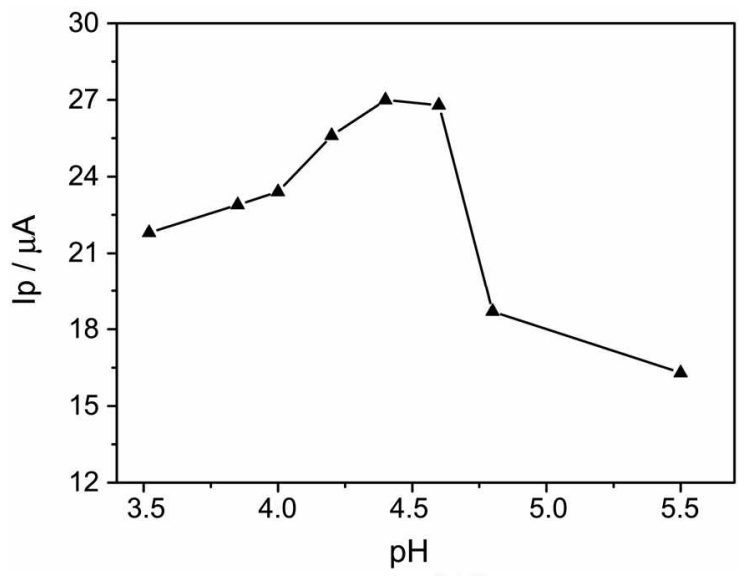

Figure 6. The dependence of the oxidation peak current on $\mathrm{pH}$.

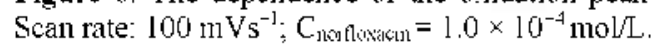




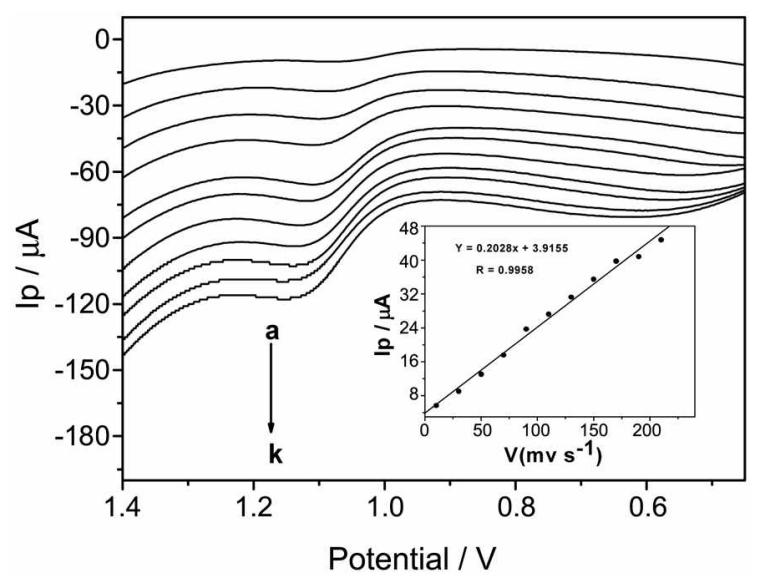

Figure 7. Cyclic voltammagrams of $1.0 \times 10^{-4} \mathrm{~mol} / \mathrm{L}$ norfloxacin on the the poly(methyl red) film modified GCE in acetate bufter $(0.05 \mathrm{~mol} / \mathrm{L}, \mathrm{pH} 4.4)$ with different scan rates. (a)-(k) were 10,30 , $50,70,90,110,130,150,170,190$ and $210 \mathrm{mVs}^{-1}$, respectively: Inset is the plot of oxidation peak currents vs. scan rates.

voltanmetry. As shown in Figure 7. the oxidation peak currents of NFX increased linearly with the scan rates in the range $10-210 \mathrm{mV} \mathrm{s}^{-1}$. The correlation coefficient was 0.9958 . This suggested that the process of electrode reaction was controlled by adsorption of NFX. It also showed much similarity with that at $90 \mathrm{mV} \mathrm{s}^{-1}$. Only an oxidation peak was observed even at low scan rate $(10 \mathrm{mV} / \mathrm{s})$. It suggested the electrode reaction of NFX under these conditions were totally irreversible.

Optimization of accumulation conditions. The influence of accumulation potential on the oxidation peak current of NFX was examined in the range of $-1.50 \cdot 0.50 \mathrm{~V}$. With the decrease of potential in the range of 0 to $-1.20 \mathrm{~V}$, the peak current greatly enhanced. The peak current decreased when the potential was below -1.20 . It kept unchanged when exceeded $0 \mathrm{~V}$. Thus. $-1.2 \mathrm{~V}$ was employed for accumulation potential.

To the accumulation time the experimental results showed that it has obvious effects on the oxidation peak current of NFX. As shown in Figure 8, the peak current increased with increasing accumulation time in the range of $0-60 \mathrm{~s}$. This indicated NFX was adsorbed onto the surface of modified electrode. The oxidation peak current leveled off when the accumulation time was further increased. This indicated the surface adsorption was saturated. Hence. an accumulation

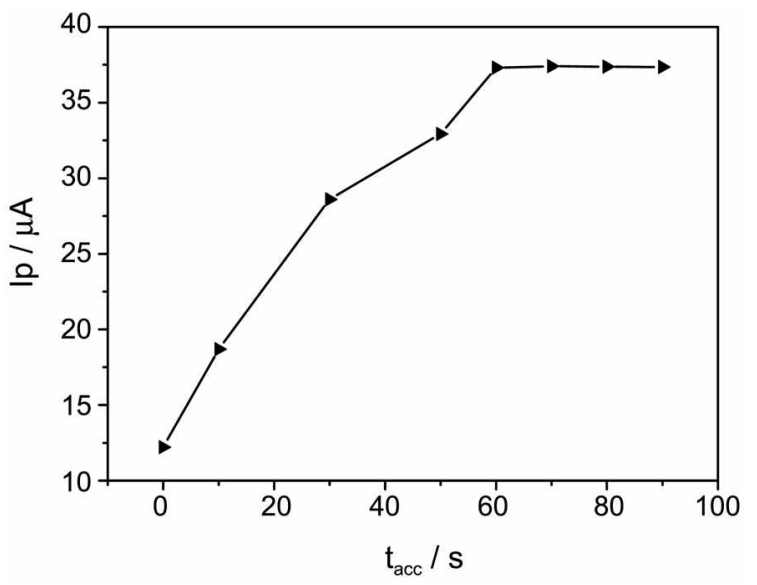

Figure 8. Effect of accumulation time on the oxidation peak current of $1.0 \times 10^{-4} \mathrm{~mol} / \mathrm{L}$ norfloxacin. Scan rate: $100 \mathrm{mVs}^{-1}$; Accumulation potential: $-1.2 \mathrm{~V}$.

Table 1. Recovery of norflosacin

\begin{tabular}{ccc}
\hline Added (mol/L) & Found $(\mathrm{mol} / \mathrm{L})$ & Recovery $(\%)$ \\
\hline $1.00 \times 10^{-6}$ & $1.03 \times 10^{-6}$ & 103.3 \\
$5.00 \times 10^{-6}$ & $5.18 \times 10^{-6}$ & 103.5 \\
$8.00 \times 10^{-6}$ & $7.93 \times 10^{-6}$ & 99.1 \\
$1.00 \times 10^{-5}$ & $0.97 \times 10^{-5}$ & 97.2 \\
$5.00 \times 10^{-5}$ & $5.14 \times 10^{-5}$ & 102.8 \\
$8.00 \times 10^{-5}$ & $7.84 \times 10^{-5}$ & 98.0 \\
$1.00 \times 10^{-4}$ & $0.98 \times 10^{-4}$ & 97.6 \\
\hline
\end{tabular}

time of $70 \mathrm{~s}$ was chosen for the following experiments.

Calibration curve. The relationship between the oxidation peak current of NFX and its concentration was investigated by LSV. The linear concentration range was found to occur from $1 \times 10^{-6}$ to $1 \times 10^{-4} \mathrm{~mol} / \mathrm{L}$, with a regression equation of Ip $=1.96+0.28 \mathrm{C}(r=0.9974, \mathrm{C}$ in $\mu \mathrm{mol} / \mathrm{L}$, Ip in $\mu \mathrm{A}$ ). For $70 \mathrm{~s}$ accumulation. the detection limit was $\mathrm{I} \times$ $10^{-7} \mathrm{~mol} / \mathrm{L}$. The relative standard deviation (R.S.D.) was $3.8 \%$ for $1 \times 10^{-5} \mathrm{~mol} / \mathrm{L}$ NFX $(n=9)$.

The long-term stability of the PMRE was evaluated by measuring the current responses at a fixed NFX concentration of $1 \times 10^{-5} \mathrm{~mol} / \mathrm{L}$ over a period of 2 weeks. The film electrode was used daily and stored in the air. The experimental results indicated that the current responses deviated only $5.4 \%$. It indicated the PMRE possessed long-term stability:

Table 2. Merits of comparable methods for detemination of norfloxacin

\begin{tabular}{|c|c|c|c|c|}
\hline Method & $\begin{array}{l}\text { Detection limit } \\
(\mathrm{mol} / \mathrm{L})\end{array}$ & $\begin{array}{c}\text { Analytical range } \\
(\mathrm{mol})\end{array}$ & Comments & Reference \\
\hline Spectrophotometry & $3.5 \times 10^{-3}$ & $9.4 \times 10^{-5}-3.1 \times 10^{-5}$ & temary tormation with eosin and palladium(II) & [22] \\
\hline Spectrofluorimetry & $1.7 \times 10^{-9}$ & $5.0 \times 10^{-8}-1.0 \times 10^{-5}$ & Application of terbium sensitized fluorescence & {$[1]$} \\
\hline HPLC & $6.8 \times 10^{-5}$ & $1.6 \times 10^{-5}-6.2 \times 10^{-5}$ & UV-detection at $278 \mathrm{~nm}$ & {$[23]$} \\
\hline $\mathrm{CE}$ & $1.0 \times 10^{-5}$ & $3.1 \times 10^{-5}-1.6 \times 10^{-4}$ & UV photo-diode array detection at $301 \mathrm{~nm}$ & {$[24]$} \\
\hline Electrochemistry & $3.5 \times 10^{-5}$ & $1.6 \times 10^{-5}-1.6 \times 10^{-4}$ & GCE & {$[17]$} \\
\hline Electrochemistry & $2.4 \times 10^{-8}$ & $3.2 \times 10^{-8}-2.0 \times 10^{-5}$ & $\beta$-cyclodextrin-modified carbon-paste electrode & {$[25]$} \\
\hline Electrochemistry & $1.0 \times 10^{-7}$ & $1.0 \times 10^{-5}-1.0 \times 10^{-4}$ & poly(methyl red) film modified GCE & Ihis paper \\
\hline
\end{tabular}


Table 3. Results for the deternination of norfloxacin in pharmaceutical fomulation

\begin{tabular}{lcccc}
\hline Samples & $\begin{array}{c}\text { Certified } \\
\text { value } \\
(\text { ming) }\end{array}$ & $\begin{array}{c}\text { Proposed } \\
\text { method } \\
\text { (mg) }\end{array}$ & $\begin{array}{c}\text { UV } \\
\text { spettrophotometry } \\
\text { (mng) }\end{array}$ \\
\hline Tablet & A & 200.0 & 196.4 & 197.5 \\
& B & 200.0 & 194.6 & 199.1 \\
& C & 200.0 & 198.9 & 201.6 \\
& D & 200.0 & 201.2 & 202.5 \\
& E & 200.0 & 20.3 & 198.7 \\
& F & 200.0 & 201.8 & 196.4 \\
\hline Capsule & A & 200.0 & 194.8 & 199.2 \\
& B & 200.0 & 195.3 & 198.2 \\
& C & 200.0 & 197.2 & 203.2 \\
& D & 200.0 & 196.9 & 201.3 \\
& E & 200.0 & 202.4 & 202.4 \\
& F & 200.0 & 203.1 & 201.4 \\
\hline
\end{tabular}

The recovery tests of NFX were also performed. The results were listed in Table 1 . The satisfactory recoveries obtained in the range from 97.2 to $103.5 \%$.

The specific features of this method were shown in Table 2. Although modified carbon-paste electrode has been reported more sensitive in detection of $\mathrm{NFX}^{25}$ and ciprofloxacin. ${ }^{36}$ which is almost very similar molecule to NFX. the proposed method is more simple in the preparation of electrode and has good reproducibility in the deternination of NFX. Also, as shown in Table 2, the present method was preferable in determination of NFX conipared with other typical methods.

Interference. To evaluate the interferences of foreign species on the determination of NFX at the level of $1 \times 10^{-6}$ $\mathrm{mol} / \mathrm{L}$. a systematic study was carried out under optimized experimental conditions described above. It was found that the film electrode can tolerate interferences from other inorganic and organic compounds. For example. 100-fold concentration of $\mathrm{Na}^{+}, \mathrm{K}^{+}, \mathrm{Cu}^{2+}, \mathrm{Ba}^{2-}, \mathrm{Zn}^{2^{-}}, \mathrm{Ca}^{2+}, \mathrm{Al}^{3-}, \mathrm{Fe}^{3+}$. $\mathrm{Cl}^{-} . \mathrm{NO}_{3}^{-}, \mathrm{HPO}_{4}^{2-} . \mathrm{SO}_{4}^{+-}, \mathrm{Cr}_{2} \mathrm{O}_{7}^{2-}$. 20-fold concentration of uric acid. oxalic acid citric acid. glucose lactic acid tartaric acid and 10-fold concentration of vitamin B1. vitamin B2. vitamin $\mathrm{B} 12$. vitamin $\mathrm{C}$ almost did not influence the current response of $1 \times 10^{-6} \mathrm{~mol} / \mathrm{L} \mathrm{NFX}$ (signal change below 5\%). It suggested that the proposed nethod has good selectivity toward NFX.

Determination of norfloxacin in the pharmaceutical preparation samples. In order to evaluate the validity of PMRE for the determination of NFX in pharmaceutical formulations. the content of NFX in NFX tablet and capsule (Henan Tianfang Pharmaceutical Co.. Henan. China) was determined with the proposed method. The analytical results were shown in Table 3 . Furthermore, in order to evaluate the present method. the NFX concentration in pharmaceutical preparation was detected by UV-spectrophotometry at 272 nm. The results shown in Table 3 proved the present method was reliable for the determination NFX in the pharmaceutical preparation samples.

\section{Conclusions}

In this work. a novel method was developed for the determination of norfloxacin based on a poly(methyl red) film modified glassy carbon electrode. The voltammetric behavior of NFX was investigated by cyclic voltammetry and linear sweep voltammetry. The film electrode greatly enlanced the oxidation peak current of NFX owing to the extraordinary properties of poly(methyl red) film. A submicromolar detection limit with a linear range of three orders of magnitude was obtained for NFX using the prepared electrode. Advantages of this method were simple, sensitive. rapid and accurate, which was demonstrated by its application in the determination of NFX in the phannaceuticals samples.

Acknowledgements. This work was supported by the Foundation of Xinyang Normal University for Young Excellent Teachers (2006) and the Research Foundation for Young Teachers of Xinyang Normal University (2007).

\section{References}

1. Marians, K. J.; Hiasa, H. J. Biol. Chem. 1997, 272.9401.

2. Drlica, K. Cur: Opin Aforobiol 1999, 2. 504

3. Zeiler. H.: Croher, K. J.Aficrobiol $1984,3.339$

4. Samanidou. V. F.: Demetriou. C. E.: Papadoyannis. I. N. Anol. Biounal. Chem. 2003. 375.623.

5. Calucei. G: Mazzeo. P.: Paumbo. G. Bioned. Chronatogr. 1993. 7. 123 .

6. Delepine, B.; Hurtaud-Pessel, D.; Sanders, P. Anatyst 1998. 123. 2743 .

7. Bhowal. S. K.: Das. T. K. Anal. Lett. 1991. 24. 25.

8. Diurdjevic. P. T.: Jelikic-Stankow. M.: Stankor. D. Anol. Chim. Acta 1995. 300.253.

9. Amin. A. S.: Elsayed. G. O.: Issa. Y. M. Analyst 1995. 120, 1189.

10. Rahman. N.: Almad, Y: Hejaz Azmi, S. N. Ew J. Hham Biopham 2004, 57,359.

11. Veiopoulou. C. T.: Ioannou. P. C.: Lianidou. E. S. J. Pham Bioned. Antal. 1997. 15. 1839

12. Espinosa-Mansilla. A.: Munoz de la Pena. A.: Salinas. F.: Gonzalez Gomez. D. Talanta 2004. 62,853.

13. Yorke. J. C.: Froc. P. J. Chomatogr A $\mathbf{2 0 0 0}, 882.63$.

14. Espinosa-Mansilla. A.: Muñoz de la Peña. A.: Gonzalez-Gomez. D.: Salinas. F. J. Chromatogr: B 2005. 822. 185.

15. Barron. D.: Timenez-Lozano. E.: Bailac. S.: Barbosa. T. Anatytica Chintica. Acta 2003. +77.21 .

16. Barron, D.; Jimenez-Lozano. E.: Cano. J.: Barbosa. J. J. Chronatog: B: Biomed Sci. Appl. 2001. 759.73.

17. Ghoneim. M. M; Radi. A; Beltagi, A. M. J. Pham. Bioned. Anal. 2001. 25.205

18. Ni. Y. N.: Wang. Y. R.: Kokot. S. Talama 2006. 69.216.

19. Park. H.: Kwon. T. G.: Park. D. S.: Shim. Y. B. Bntl. Sorean Chem. Soc. 2006, 27. 1763.

20. Li. C. Y. Bull. Korean Chem. Soc. 2006, 27,991

21. Sandulescu, R; Mirel, S; Oprean, R. J. Pham Biomed. Anal. 2000. 23.77,

22. Walily. A. F. M. E.: Belal. S. F.: Bakiy. R. S. J. Pharnt. Bionted. Anal. 1996. 14.561

23. Cordoba-Borrego, M: Cordoba-Diaz. M.: Cordoba-Diaz, D. fl tham Bioned Anal 1999.18,919.

24. Alnajjar. A.: AbuSeada. H. H.: Idris. A. M. Talanta 2007. 72.842

25. Reddy. M.: Balaji. K.: Reddy. S. T. J. Anal Chent 2007. 62. 168.

26. Zhang. S. H.: Wei. S. Bull. Korem Chem. Soc. 2006. 28. 543. 